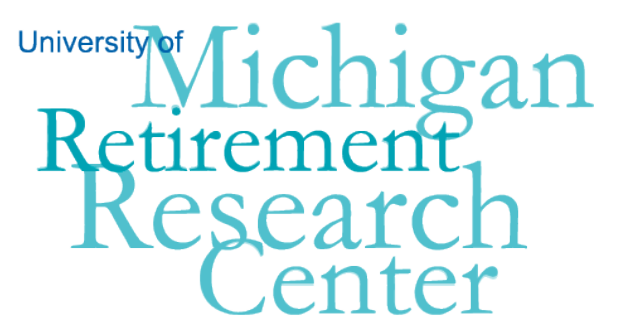

Working Paper WP 2012-271

\title{
The Interplay of Wealth, Retirement Decisions, Policy and Economic Shocks
}

\author{
John Karl Scholz and Ananth Seshadri
}

\begin{tabular}{l|l}
\hline $\mathrm{M}$ & $\mathrm{R}$ \\
\hline $\mathrm{R}$ & $\mathrm{C}$ \\
\hline
\end{tabular}

Project \#: UM12-09 



\title{
The Interplay of Wealth, Retirement Decisions, Policy and Economic Shocks
}

\author{
John Karl Scholz \\ University of Wisconsin-Madison \\ Ananth Seshadri \\ University of Wisconsin-Madison
}

September 2012

\author{
Michigan Retirement Research Center \\ University of Michigan \\ P.O. Box 1248 \\ Ann Arbor, MI 48104 \\ www.mrrc.isr.umich.edu \\ (734) 615-0422
}

\section{Acknowledgements}

This work was supported by a grant from the Social Security Administration through the Michigan Retirement Research Center (Grant \# 5 RRC08098401-04-00). The findings and conclusions expressed are solely those of the author and do not represent the views of the Social Security Administration, any agency of the Federal government, or the Michigan Retirement Research Center.

\section{Regents of the University of Michigan}

Julia Donovan Darrow, Ann Arbor; Laurence B. Deitch, Bloomfield Hills; Denise Ilitch, Bingham Farms; Olivia P. Maynard, Goodrich; Andrea Fischer Newman, Ann Arbor; Andrew C. Richner, Grosse Pointe Park; S. Martin Taylor, Gross Pointe Farms; Katherine E. White, Ann Arbor; Mary Sue Coleman, ex officio 


\title{
The Interplay of Wealth, Retirement Decisions, Policy and Economic Shocks
}

\begin{abstract}
We develop a model of health investments and consumption over the life cycle where health affects longevity, provides flow utility, and retirement is endogenous. The decision to retire depends on a number of factors including earnings and health shocks, demographic characteristics, preferences, pensions, and Social Security. We incorporate these features in a computational model of optimal wealth and retirement decisions. We use the model to study how workers would respond to an increase in the early eligibility age of retirement (EEA), and to what extent would the bad economy alter retirement plans. We find that increasing the EEA results in sizeable responses to the age of retirement but does not affect health outcomes very much. A 20 percent reduction in wealth induces households to delay retirement by one year, on average, with poor households being relatively unaffected.
\end{abstract}

\section{Authors' Acknowledgements}

The research reported herein was pursuant to a grant from the U.S. Social Security Administration (SSA) funded as part of the Retirement Research Consortium (RRC). The findings and conclusions expressed are solely those of the authors and do not represent the views of SSA, any agency of the Federal Government or the RRC. We are also grateful to the NIH for generous financial support through grant R01AG032043. We thank Mike Anderson and HsuehHsiang Li for fine research assistance. 


\section{Introduction}

In this paper we seek to enhance understanding of the relationship between social security, wealth and retirement decisions. Economic models of life-cycle consumption and wealth accumulation (that start at the beginning of working life) either treat retirement as being exogenous, and therefore not affected by unforeseen household circumstances, or model behavior of a small number of stylized household "types," which ignores heterogeneity in earnings, health, and demographic change that is essential to understanding the distribution of wealth. In this paper we develop a rich life-cycle model of optimal consumption and retirement decisions. We use the model to study the complex interplay of saving/consumption decisions, retirement, social security policy and macroeconomic shocks.

An obvious way for some households to respond to perceived (or actual) shortfalls in retirement wealth accumulation is to work longer than they originally anticipated. Similarly, households with net worth considerably higher than the amount needed to equate the discounted marginal utility of consumption may choose to retire earlier than initially expected. Of course, these households may also be concerned with the prospect of facing unusually high out-of-pocket medical or other necessary expenses or they may wish to leave assets to children or philanthropic organizations. We use our model to study the way retirement expectations, wealth accumulation, shocks to earnings and health, and social security policy interact to influence retirement decisions.

A vast literature examines the effects of OASI and incremental reforms of it on the retirement age (see, for example, Danziger et al., 1981; Lumsdaine and Mitchell, 1999; Krueger and Meyer, 2002). Lumsdaine and Mitchell (1999) suggest that OASDI reduces the employment rate of men at age 62 by 15 percentage points; Gustman and Steinmeier (1986) report 19 percentage points; and Danziger et al. (1981) report 12 percentage points after summarizing early work on the topic. Comparing the results of studies over time is complicated, as the average age of male retirement fell steadily for most of the last century, 
though the decline leveled out over the last 20 years. Mermin, Johnson, and Murphy (2006) report that the mean expected probability of full-time work after age 65 grew to 33 percent (from 27 percent) among workers age 51 to 56 between 1992 and 2004. They attribute the changes primarily to the declining generosity (and increasing cost) of retiree health insurance, increase in educational attainment (which results in less physically demanding and less tedious jobs), and lower defined-benefit pension coverage (and the associated strong retirement incentives found in DB plans). This prior work is critical for our study for at least three reasons: first, it provides an outstanding knowledge base to learn from and build on; second, it provides critical underlying parameters for our proposed calibrated, numerical work; and third, it provides facts (and in some cases, moments) that can be used to identify model parameters where no direct evidence is available. As mentioned in the introduction, however, existing studies do not jointly model household consumption and retirement decisions, starting from the beginning of working life, accounting for expectations, demographic changes in the household, health and earnings shocks, and the policy environment (including taxes, transfers, and social security).

McGarry (2004) offers a detailed, thorough look at the relationship between retirement expectations and health status, focusing on subjective reports of health. Specifically, she focuses on workers and finds subjective reports of health have important effects on retirement and that these effects are stronger than those of financial variables. Moreover, changes in retirement expectations are affected much more by changes in health than by changes in income or wealth. While her treatment of health and retirement expectations is very informative, the role of wealth accumulation in retirement is less well developed. In particular, one obvious way that low-wealth households (relative to optimal) can adapt, given their expected retirement date, is to postpone retirement. Similarly, households with substantially more wealth than necessary to equate the discounted marginal utility of consumption across periods (given an expected retirement rate) may choose to retire earlier than initially planned. We are not aware of studies that explore the relationship between 
retirement and wealth accumulation that also incorporate a rigorous standard for optimal behavior.

Retirement decisions are interlinked with health and consumption decisions, yet the ways that consumption and health interact with retirement are hard to untangle. Health changes, such as disability or illness, affect labor market decisions and hence income and consumption possibilities. But causality also operates in the other direction, where consumption decisions such as smoking or exercise affect health. There are also unobserved differences between people in their ability to produce and maintain health and human capital, leading to correlations between health and lifetime income and wealth. This paper, thus, examines links between health, consumption and wealth and the interplay with retirement decisions.

There are many possible ways to examine these links. Our analysis starts from ideas dating back at least to Grossman (1972), who argued that health is the cumulative result of investment and choices (along with randomness) that begin in utero. We model household utility as being a function of consumption and health, where individuals make optimizing decisions over consumption and the production of health. In our model, health affects not just utility but also longevity. Surprisingly, given the centrality of health to economic decision-making and well-being, numerical models of lifecycle consumption choices generally treat health in a highly stylized fashion. Authors commonly do not model health as being an argument of utility and do not allow health to affect retirement or longevity (see, for example, Hubbard, Skinner, and Zeldes, 1995; Engen, Gale, Uccello, 1999; Palumbo, 1999; and Scholz, Seshadri, Khitatrakun, 2006). Instead, medical expense shocks that proxy for health shocks affect the lifetime budget constraint. Households in these papers respond to exogenous medical expense shocks by decreasing consumption, saving for precautionary reasons.

In this paper, we formulate a life-cycle model with endogenous retirement that we solve household-by-household, where health investments (including time-use decisions) af- 
fect longevity and health affects utility. By modeling investments in health, longevity becomes an endogenous outcome, which allows us to study the effects of economic shocks and changes in policy on mortality, wealth and retirement. Our model also captures the effects of poor health on sick time and hence on earnings and retirement.

We, of course, are not the first to examine the links between health, consumption, and wealth. Clear discussions are given in Smith (2005) and Case and Deaton (2005) and many other places. Palumbo (1999) and De Nardi, French and Jones (2010) are more closely related to our work. In their models, the only response that households have to the realization of medical expense shocks is to alter consumption. Death occurs through the application of life tables with random longevity draws. ${ }^{1}$ They document that late-in-life health shocks, including nursing home expenses and social insurance, play a substantial role in old age wealth decumulation.

We build on the past lifecycle endogenous retirement as well as consumption and health literature including our own previous work supported by the SSA in at least three ways. First, our specification of utility is different. Most prior papers that add health or medical expenditures to utility assume it is separable from consumption in preferences. ${ }^{2}$ Health is a specific object of interest in our approach and we model health production. We allow consumption and health to be complements or substitutes in preferences. In practice, we find consumption and health are complements and complementarity is quantitatively

\footnotetext{
${ }^{1}$ In section 9 of De Nardi, French and Jones (2010) they write down and estimate key structural parameters of a model where consumption and medical expenditures are arguments of utility, and where health status and age affect the size of medical-needs shocks. Their model is estimated on a sample of single individuals age 70 and over. They find that endogenizing medical expense shocks has little effect on their findings that medical expenses are a major saving motive and that social insurance affects the saving of the income-rich as well as that of the income-poor.

Two other related papers model intertemporal consumption decisions and include health in the utility function. Fonseca, Michaud, Galama, and Kapteyn (2009) write down a model similar to ours and solve the decision problem for 1,500 representative households. Consumption and health are separable in utility in their model and the focus of their work is on explaining the causes behind the increases in health spending and life expectancy between 1965-2005. Yogo (2009) solves a model similar to ours for retired, single women over 65 to examine portfolio choice and annuitization in retirement.

${ }^{2}$ An exception is Murphy and Topel (2006) who use a utility function that features consumption-health complementarity to value improvements in health.
} 
important to understanding the evolution of health and wealth as individuals age. In particular, consumption will optimally decline in old age, tracking the inevitable deterioration of health, which implies consumption will be shifted to earlier periods in the life cycle relative to models that ignore health-consumption interactions. The anticipated decline in health and consumption late in life has important implications for retirement decisions.

Second, most papers do not examine health investments and consumption decisions of households younger than 65. Health capital, however, may be well-formed by prior decisions and expenditures by the time an individual reaches 65 . We model health production from the start of the working life. ${ }^{3} \quad$ Forward-looking households will respond to income shocks, health shocks, or to changes in institutions by altering their health investments and consumption during their working lives. This new feature of our model is particularly important in the analysis of policy changes such as changes in the early eligibility age of retirement (EEA). The concern with increasing the EEA is that households in poor health near retirement may be unable to work so as to maintain consumption and health levels modeling health alongside retirement decisions is important in addressing this concern.

Third, the literature including Palumbo (1999) and De Nardi, French and Jones (2010) has shown that anticipated and realized medical expenses are an important determinant of wealth decumulation patterns in old age. The focus of our work differs. We develop a model of consumption and longevity to study how health and income shocks affect consumption plans, and how health and income shocks affect investments in health capital over the lifecycle. If death occurs when health falls below a given threshold, households may respond to policy or exogenous shocks by reducing or increasing consumption and hence altering longevity relative to a world where health is not an argument in preferences. This feature allows us to capture the impact of policy changes and economic shocks on life tables.

\footnotetext{
${ }^{3}$ Health is undoubtedly influenced by shocks and decisions made in utero and in childhood. We do not have data on these experiences, however, so lack of data and computational demands lead us to start our analysis at the beginning of working life.
} 
After calibrating our model to match key moments for the average household, we find the model is able to match the cross-sectional variation in medical expenses, longevity, the stock of health and retirement decisions in the Health and Retirement Study. Finally, we conduct policy experiments to highlight various features of the model. Specifically, we look at two important exogenous changes - a shock to wealth and an increase in the EEA from 62 to 64 .

\section{Model Economy ${ }^{4}$}

We assume a household maximizes utility by choosing consumption, health investments, and leisure. Time spent working depends on the health status of the individual (we assume that sick time is related to the health stock) and rest of the time is divided up between leisure and health investments. Retirement is endogenous. Even though adding health capital and endogenous retirement involves only two additional choice variables (relative to a standard life-cycle intertemporal consumption problem), it is a significant complication. In addition to affecting longevity, households derive direct satisfaction from health. Lifetime utility at any age, $V_{j}$, is given by an Epstein-Zin, Kreps-Porteus formulation of recursive preferences

$$
V_{j}=\underset{c, l, h}{\operatorname{Max}}\left[n_{j} U\left(c_{j} / n_{j}, l_{j}, h_{j}\right)^{1-\gamma}+\beta\left(E_{t} V_{j+1}^{1-\theta}\right)^{(1-\gamma) /(1-\theta)}\right]^{\frac{1}{1-\gamma}} .
$$

In the above formulation, $\theta$ measures the coefficient of risk aversion, $\frac{1}{\gamma}$ is the intertemporal elasticity of substitution and $U(\cdot)^{1-\gamma}$ denotes period utility which is non-separable with

\footnotetext{
${ }^{4}$ This section describing the model and our calibration is almost identical to the parallel discussion in our August 2012 paper "Health and Wealth in a Lifecycle Model." A project with some overlap with a title "The Influence of Public Policy on Health, Wealth and Mortality" was circulated in September 2011. We have made many changes to the model and analysis since September 2011. The most important include a new specification of recursive preferences, which gives us the ability to disentangle risk from uncertainty; endogenous retirement; modeling the evolution of health status of husband and wife separately; improved modeling of the private insurance status of households as well as the transitioning between private insurance and Medicare; and allowing health to affect earnings and vice versa. We have also updated our data.
} 
the certainty equivalent of future utility. Notice that when $\theta=\gamma$, we get the standard time-additive separable case.

There are three related reasons we chose this specification of preferences. First, it isolates the degree of risk aversion from the intertemporal elasticity of substitution. These features of preferences may have independent effects on health and other household choices. Second, as noted in Rosen (1988), with endogenous mortality, standard time-additive preferences are not invariant to affine transformations. This arises due to the fact that the household attributes zero utility to death and the agent needs to compare the utility of any optimal schedule with zero to determine whether or not it is worthwhile to live longer. Third, with common time-additive, separable CRRA preferences, $U(c)=\frac{c^{1-\sigma}}{1-\sigma}, \sigma<1$ for utility to be a positive number. But most estimates and calibration exercises suggest $\sigma$ exceeds one. Our formulation allows $\sigma$ to exceed one. ${ }^{5}$

The expectation operator $E_{t}$ denotes the expectation over uncertain future earnings before retirement and uncertain health shocks throughout life, $\beta$ is the discount factor, $j$ is age, $c$ is consumption, and $h$ is a composite stock of health for men and women in the household, and $l$ is leisure. $n_{j}$ is a household scale parameter and is a function of the number of adults, $A$, and children, $K$, in the household, so $n=g\left(A_{j}, K_{j}\right)$. Households spend an indivisible amount of time $\omega(h)$ working each period and spend the rest of their time endowment $1-\omega(h)$ on either leisure or on activities that augment health investments. We assume that $\omega(h)=\bar{\omega}-s(h)$, which draws from Grossman's formulation of sick time: households experience some loss in labor supply depending on sick time, $s(h)$, which is inversely related to their health status. ${ }^{6}$ Upon retirement, households split their time

\footnotetext{
${ }^{5}$ Hall and Jones (2007), following others, use conventional CRRA preferences but add a large enough constant to guarantee that utility is positive.

${ }^{6}$ In our modeling of sick time, we assume that poor health adversely affects the time that an individual spends in the labor market. While poor health may well affect investments in human capital and consequently the wage rate that an individual faces, we observe data on earnings and we do not observe either hours worked or the wage rate. Consequently, data limitations prevent us from disentangling the impact of bad health on labor supply from its effect on hours worked. Furthermore, the analysis in French (2005) suggests that health status has a much larger impact on labor supply and labor force participation than
} 
endowment of 1 unit between leisure and health investments.

A challenge when modelling health is that there is at best mixed evidence that marginal expenditures on medical care in the U.S. buy greater health, and hence longevity. ${ }^{7}$ This phenomenon is sometimes referred to as "flat of the curve" medicine. It is noteworthy just how hard scholars need to look to find evidence that expenditures on medical care have a discernible, positive effect on health and particularly mortality outcomes. Card, Dobkin, and Maestas (2008), for example, is one of a small number of studies that find expenditures are positively correlated with survival. Their work is based on a very large sample of people admitted to emergency rooms in California: they find the positive effects of spending apply to a small subset of the conditions that lead people to show up in emergency rooms. Doyle (2010) shows that men who have heart attacks when vacationing in Florida have higher survival probabilities if they end up being served by high- rather than low-expenditure hospitals. Other studies suggest that marginal medical expenditures have little discernible effect on health.

It is nevertheless clear that money can sometimes improve health. Antibiotics can effectively cure strep throat. Treatment can help people survive cancer. A good orthopedist can help people recover fully from broken bones. We assume that the household possesses a health stock and investments can improve health. The accumulation process of the stock of health is given by

$$
h_{j+1}=f\left(m_{j}, i_{j}\right)+\left(1-\delta_{h}\right) h_{j}+\varepsilon_{j}, j \in\{S, \ldots\}
$$

The stock of health at the next age, $h_{j+1}$, is determined by the production of health, given by $f\left(m_{j}, i_{j}\right)$. Health capital is produced using time, $i_{j}$, which could be exercise or other on the wage rate.

${ }^{7}$ See, for example, the Dartmouth Health Atlas (http://dartmouthatlas.org/), which documents little relationship between regional variation in health spending and health outcomes. Finkelstein and McKnight (2008) find little effect of Medicare on mortality when the program was initiated. Chay, Kim and Swaminathan (2010) challenge this assessment. 
health-producing activities, and medical expenditures. Total medical expenditures, $m_{j}$, are a function $M(\cdot)$ of out-of-pocket medical expenses, $m_{j}^{o o p}$. In the above equation, $\delta_{h}$ stands for the depreciation rate of health. Introducing age-dependent shocks to health is both realistic and necessary if we are interested in matching biological processes and the data. These age-dependent shocks are denoted by $\varepsilon_{j}$, which we allow to vary by gender. In typical lifecycle models, medical expenditures have only financial consequences. Here, medical expenditures affect health capital which, in turn, affects utility and longevity. The modeling approach mimics the modeling of human capital - additions to human capital can be either consumption or investment as in Becker (1964), Mincer (1974) and the subsequent, vast human capital literature.

The probability of surviving into the next period is given by the function $\Psi(h)$. This function satisfies two properties. As $h$ goes to $\infty, \Psi(h)$ converges to 1 . Second, $\Psi(h)=0$ for $h \leq 0$. This ensures that as soon as $h$ goes to zero, the household dies.

Consumption, the age of retirement, and health investments are chosen to maximize expected utility subject to the constraints.

$$
\begin{gathered}
y_{j}=e_{j}\left(h_{j}\right)+r a_{j}+T\left(e_{j}\left(h_{j}\right), a_{j}, j, n_{j}\right), j \in\{S, \ldots, R\} \\
y_{j}=S S\left(\sum_{j=S}^{R} e_{j}\left(h_{j}\right)\right)+D B\left(e_{R}\left(h_{R}\right)\right)+r a_{j}+T_{R}\left(e_{R}\left(h_{R}\right), \sum_{j=S}^{R} e_{j}\left(h_{j}\right), a_{j}, j, n_{j}\right), j \in\{R+1, \ldots\} \\
c_{j}+a_{j+1}+m_{j}^{o o p}=y_{j}+a_{j}-\tau\left(e_{j}\left(h_{j}\right)+r a_{j}\right), j \in\{S, \ldots, R\} \\
c_{j}+a_{j+1}+m_{j}^{o o p}=y_{j}+a_{j}-\tau\left(S S\left(\sum_{j=S}^{R} e_{j}\left(h_{j}\right)\right)+D B\left(e_{R}\left(h_{R}\right)\right)+r a_{j}\right), j \in\{R+1, \ldots\}
\end{gathered}
$$

In these expressions $y$ is income, $e(h)$ is earnings, which depends on health stock, $a$ is assets, $r$ is the interest rate, $T$ is a transfer function, $R$ is the age of retirement, and $S$ is the age that a household member enters the labor market. Social security $(S S)$ is a function of 
lifetime earnings, defined benefit pensions $(D B)$ are a function of earnings in the last year of life, $\tau$ is a payroll and income tax function, and the transfer function for retirees $\left(T_{R}\right)$ is a function of social security, defined-benefit pensions, assets, age, and family structure.

\subsection{Retired Household's Dynamic Programming Problem}

A retired, married household between ages $R$ and $D$ obtains income from social security, defined-benefit pensions, and preretirement assets. The dynamic programming problem at age $j$ for a retired household is given by

$$
\begin{gathered}
V\left(e_{R}, E_{R}, a, j, h_{h}, h_{w}\right)= \\
\max \left\{\left[\int_{\varepsilon_{h}} \int_{\varepsilon_{w}} V\left(e_{R}, E_{R}, a^{\prime}, j+1, h_{h}^{\prime}, h_{w}^{\prime}\right)^{1-\theta} d \Xi_{h}\left(\varepsilon_{h}\right) d \Xi_{w}\left(\varepsilon_{w}\right)\right]^{(1-\gamma) /(1-\theta)}\right.
\end{gathered}
$$

subject to

$$
\begin{gathered}
y=S S\left(E_{R}\right)+D B\left(e_{R}\right)+r a+T_{R}\left(e_{R}, E_{R}, a, j, n\right) \\
c+a^{\prime}+m_{h}^{o o p}+m_{w}^{o o p}=y+a-\tau\left(S S\left(E_{R}\right), D B\left(e_{R}\right)+r a\right) \\
h_{h}^{\prime}=F\left(M\left(m_{h}^{o o p}\right), i\right)+\left(1-\delta_{h}\right) h_{h}+\varepsilon_{h} \\
h_{w}^{\prime}=F\left(M\left(m_{w}^{o o p}\right), i\right)+\left(1-\delta_{h}\right) h_{w}+\varepsilon_{w} \\
h=\Delta\left(h_{h}, h_{w}\right)
\end{gathered}
$$

In the above equation, the value function, $V\left(e_{R}, E_{R}, a, j, h_{h}, h_{w}\right)$, denotes the expected present discounted value of maximized utility from age $j$ until the date of death, the ' superscript denotes the corresponding value in the following year; and, as noted before, $\Psi(h)$ denotes the probability of survival between ages $j$ and $j+1$ for the husband and 
the wife respectively. $m^{o o p}$ are out-of-pocket medical expenses for the husband and wife. Total earnings up to the current period are denoted by $E_{R}$, while the last earnings draw at the age of retirement is $e_{R}$. Note that these values do not change once the household is retired. We integrate over the distribution of health shocks facing the husband and wife in the married couple.

\subsection{Working Household's Dynamic Programming Problem}

A working single household between the ages $S$ and $R$ obtains income from labor earnings and preretirement assets. ${ }^{8}$ The dynamic programming problem at age $j$ for a working household is given by

$$
\begin{gathered}
W\left(e, E_{-1}, a, j, h\right)= \\
\max \left\{\begin{array}{c}
n U(c / n, 1-\omega(h)-i, h)^{1-\gamma}+\beta \Psi(h) \\
{\left[\int_{\varepsilon} \int_{e^{\prime}} W\left(e^{\prime}, E, a^{\prime}, j+1, h^{\prime}\right)^{1-\theta} d \Xi(\varepsilon) d \Omega\left(e^{\prime}\right)\right]^{(1-\gamma) /(1-\theta)}}
\end{array}\right\}^{\frac{1}{1-\gamma}}
\end{gathered}
$$

subject to

$$
\begin{gathered}
y=e(h)+r a+T(e(h), a, j, n) \\
c+a^{\prime}+m^{o o p}=y+a-\tau(e(h)+r a) \\
h^{\prime}=F\left(M\left(m^{o o p}\right), i\right)+\left(1-\delta_{h}\right) h+\varepsilon \\
E=E_{-1}+e(h)
\end{gathered}
$$

$V\left(e, E_{-1}, a, j, h\right)$ denotes the expected present discounted value of lifetime utility at age j. $E_{-1}$ are cumulative earnings up to the current period. We integrate over health and non-health-related earnings shocks. As noted earlier, health shocks also affect earnings

\footnotetext{
${ }^{8}$ For brevity, we do not write down the dynamic programming problem for single retired and married working households.
} 
through their effect on sick time. The other variables are defined above.

As noted earlier, the age at which the household retires is endogenous. The decision problem at this age is much the same as the working household's decision problem with one exception, the continuation value is what the household will realize upon retiring, given by the value function $W\left(e, E_{-1}, a, j, h\right)$. The irreversible retirement decision is affected by changes in social security, defined benefit pensions, and by the incidence of health shocks as the household ages. We compute the optimal retirement age by solving the household decision problem for various choices of the (discrete) retirement age and then choosing the retirement age that maximizes lifetime utility.

\section{Model Parameterization and Calibration}

In this section, we specify functional forms and parameter values that we use to solve the model. We start by specifying functional forms for utility and health production. We then set some parameter values based on information from the literature or from reduced form estimates from the HRS. We identify the other parameters by fitting the predictions of the model for the average household to data on wealth accumulation, medical expenses, retirement age and survival probabilities. Once we have these parameter values, we then solve the model household-by-household and examine predictions for each household in our sample.

Preferences: Recall that preferences are recursive. We assume that momentary household utility has a constant relative risk-averse form. We further assume the subutility function over consumption and health has a constant elasticity of substitution. Hence the period utility takes the form

$$
U(c / n, h, l)^{1-\gamma}=\left[\lambda\left(c^{\eta} l^{1-\eta}\right)^{\rho}+(1-\lambda) h^{\rho}\right]^{\frac{1-\gamma}{\rho}} .
$$


The elasticity of substitution between the consumption-leisure composite and health is $1 /(1-\rho)$. The parameter $\gamma$ is the inverse of the intertemporal elasticity of substitution. The discount factor $(\beta)$ is set at 0.96 , a value similar to the 0.97 value used in Hubbard, Skinner, and Zeldes (1995); and Engen, Gale, and Uccello (1999). We also set $\eta=0.36$ from Cooley and Prescott (1995). Finally, we set $\theta$, the coefficient of risk aversion equal to 3, a value commonly used in many studies including Hubbard, Skinner, and Zeldes (1995). We calibrate $\gamma$.

Health aggregator: Our analysis of consumption and wealth accumulation is naturally at the household level. But health is clearly individual. We model individual investments in health that we then aggregate to the household level using a simple CES function

$$
h=\Upsilon\left(h_{h}, h_{w}\right)=\left[\vartheta\left(h_{h}\right)^{v}+(1-\vartheta)\left(h_{w}\right)^{v}\right]^{\frac{1}{v}} .
$$

Equivalence Scale: This is obtained from Citro and Michael (1995) and takes the form

$$
n=g(A, K)=(A+0.7 K)^{0.7}
$$

where $A$ indicates the number of adults and $K$ indicate the number of children in the household.

Rate of Return: We assume an annualized real rate of return, $r$, of 4 percent. This assumption is consistent with McGrattan and Prescott (2003), who find that the real rate of return for both equity and debt in the United States over the last 100 years, after accounting for taxes on dividends and diversification costs, is about 4 percent.

Taxes: We model an exogenous, time-varying, progressive income tax that takes a form used by Gouveia and Strauss $(1994,1999)$

$$
\tau(y)=a\left(y-\left(y^{-a_{1}}+a_{2}\right)^{-1 / a_{1}}\right),
$$


where $y$ is in thousands of dollars. We estimate parameters $a, a_{1}$, and $a_{2}$ using information on taxes paid and incomes by income class drawn from Statistics of Income volumes (produced by the Internal Revenue Service) available electronically through the Boston Public Library. The function characterizes U.S. effective, average household income tax rates between 1950 and 2008.

Earnings and Earnings Expectations: Earnings data through 2007 come from three sources: Social Security Administration Summary Earnings files, SSA earnings detail files (W2 information), and HRS self-reports.

Earnings in the Summary Earnings files are top-coded. Starting in 1978 we have untop-coded W2 data for many individuals. Starting in 1992 we have HRS self-reports of earnings. If available, we use W2 data or self-reports to address top-coding. For top-coded observations from 1951 to 1977, we estimate a censored regression model to predict true earnings for top-coded observations. ${ }^{9}$ For the remaining top-coded observations from 1978 to 2007 we use a similar empirical model, adding labor force status to the covariates after 1992. We set missing earnings to zero in years following the respondent's last year of work or retirement year, for respondents who report never having worked, and for respondents younger than age 17. We impute the remaining missing earnings using a variant of our empirical earnings model: rather than using the respondent's percentile in the earnings distribution, we use the respondent's average real earnings in the past/next five years.

Earnings expectations are a central influence on life-cycle consumption and health accumulation decisions, both directly and through their effects on expected pension and social security benefits. ${ }^{10}$ We aggregate individual earnings histories into household earnings his-

\footnotetext{
${ }^{9}$ The empirical model includes the following covariates: gender, education, birth year, race, census region, marital status, average percentile in the earnings distribution over the previous 5 years (if available), average percentile in the earnings distribution over the next 5 years (if available), number of children in the household, total years reported working, and average real household wealth over the HRS study years $(1992,1994, \ldots$. 2008). The non-time-varying covariates are drawn from the first wave the respondent appears in the HRS.

${ }^{10}$ Due to data and computational limitations, we assume that earnings expectations are independent of health status. Credibly relaxing this assumption would require data on wage rates, hours, and health
} 
tories, putting earnings in constant dollars using the CPI-U. The household model of log earnings (and earnings expectations) is

$$
\begin{gathered}
\log e_{j}=\alpha^{i}+\beta_{1} A G E_{j}+\beta_{2} A G E_{j}^{2}+u_{j} \\
u_{j}=\rho u_{j-1}+\epsilon_{j}
\end{gathered}
$$

where, as mentioned above, $e_{j}$ is the observed earnings of the household $i$ at age $j$ in 2008 dollars, $\alpha^{i}$ is a household specific constant, $A G E_{j}$ is age of the head of the household, $u_{j}$ is an $\mathrm{AR}(1)$ error term of the earnings equation, and $\epsilon_{j}$ is a zero-mean i.i.d., normally distributed error term. The estimated parameters are $\alpha^{i}, \beta_{1}, \beta_{2}, \rho$ and $\sigma_{\epsilon}$.

We divide households into six groups according to education, marital status and the number of earners in the household, resulting in six sets of household-group-specific parameters, which we then estimate separately for each of the five HRS cohorts (resulting in 30 sets of parameters). ${ }^{11}$ Estimates of the persistence parameter, $\rho$, across groups range from 0.69 to 0.82 .

Assuming a 40 hour workweek and 112 hours of non-sleeping time per week, we set the value of full-time work, $\bar{\omega}$, to 0.36 .

Transfer Programs: We model public income transfer programs using the specification in Hubbard, Skinner and Zeldes (1995). Specifically, the transfer that a household receives while working is given by

$$
T=\max \{0, \underline{c}-[e+(1+r) a]\}
$$

prior to when households enter the HRS.

${ }^{11}$ The groups are (1) married, head without a college degree, one earner; (2) married, head without a college degree, two earners; (3) married, head with a college degree, one earner; (4) married, head with a college degree, two earners; (5) single without a college degree; and (6) single with a college degree. We estimate the parameters separately for the AHEAD, CODA, HRS, War Babies, and Early Boomer cohorts. A respondent is an earner if his or her lifetime earnings are positive and contribute at least 20 percent of the lifetime earnings of the household. 
whereas, the transfer that the household receives upon retiring is

$$
T=\max \left\{0, \underline{c}-\left[S S\left(E_{R}\right)+D B\left(e_{R}\right)+(1+r) a\right]\right\}
$$

This transfer function guarantees a pre-tax income of $\underline{c}$ and implies that earnings, retirement income, and assets reduce public benefits dollar for dollar. To set $\underline{c}$ we use information from Moffitt (2002) for 1960, 1964, 1968 to 1998 and extend the series using data from The Urban Institute, Mathematica Policy Research Inc., Center for Medicare and Medicaid Services, and the UKCPR National Welfare Data. ${ }^{12}$ These data are at the state level so we take a weighted average according to state population in each year. Benefits have trended down since 1974 when the consumption floor for a single parent, two-child family peaked at $\$ 14,767$ (in year 2008 dollars). In 2007 the same family would have received transfers worth $\$ 11,308$.

Defined benefit pensions: Pension expectations and benefits come from an empirical defined-benefit pension function estimated with HRS data. The function includes indicator variables for having a defined benefit plan and belonging to a union, and variables for years in the pension by the retirement date, household earnings in the last year of work and the fraction of household earnings earned by the male and the fraction earned by the female.

Health production: We assume that the production of health is given by $F(M(m), i)=$ $A_{t}\left(m^{\chi} i^{1-\chi}\right)^{\xi}$, where total medical expenses are a function of out-of-pocket expenses, $m=$ $M\left(m^{o o p}\right)$ and health is also produced with time, $i$. We assume $A_{t}$ grows at 3 percent per year reflecting aggregate improvements in productivity of health technology. Total medical expenditures are related to out-of-pocket expenditures by a linear function that depends on insurance status. For the uninsured, this function takes the form, $m=\left\{\begin{array}{c}m^{o o p}+c, \quad \text { shock } \\ m^{o o p}, \quad \text { no shock }\end{array}\right.$. In the absence of a health shock, health care expenditures come directly out of the uninsured household's pocket. In the event that the uninsured

\footnotetext{
${ }^{12}$ See http://www.ukcpr.org/AvailableData.aspx
} 
household suffers an adverse health shock, a baseline level of care, $c$, is provided via charity care.

For an insured household, total medical expenses are paid partially out-of-pocket and partially through insurance, $m=\underbrace{D+\zeta(m-D)}_{\mathrm{OOP}}+\underbrace{(1-\zeta)(m-D)}_{\text {insurance }}$. There are two parts of out-of-pocket expenses, the deductible $D$ and a fraction $\zeta \in[0,1]$ of the balance, $(m-D)$, that remains after the deductible has been paid.

We use the Medical Expenditure Panel Survey (MEPS) to calibrate the parameters of the medical expense model for six different insurance categories. Households in which the head is younger than 65 may be: uninsured, insured with public insurance only, or insured with any sort of private insurance. Three more categories capture older households: Medicare only, Medicare with supplemental public insurance (but no private), or Medicare and any private insurance.

To calibrate the value of charity care for the uninsured, we draw from Doyle (2005) who suggests the previous estimates "center around forty percent less care for the uninsured."13 The average total medical spending for the insured (under age 65) in the event of a health shock in the 2008 MEPS data was $\bar{m}_{i}=\$ 3,768$. Average out-of-pocket spending for the uninsured was $\bar{m}_{u}^{o o p}=\$ 861$. Using the relationship that $0.6 \bar{m}_{i}=\bar{m}_{u}=\bar{m}_{u}^{o o p}+\bar{c}$ we recover the average value of charity care in the event of an adverse health shock, $\bar{c}=\$ 1,400$.

To calibrate the "generosity parameter," $\zeta$, for each of the insurance types, we use estimates of the average deductible, average total medical spending and average out-ofpocket spending. The spending model implies that $m^{o o p}=D+\zeta(m-D)$, which can be rewritten to solve for $\zeta_{i}=\frac{m_{i}^{\text {oop }}-D_{i}}{\left(m_{i}-D_{i}\right)}, i \epsilon\{1,2, \ldots, 5\}$. The resulting values are $\zeta=0.039$ for households under 65 with any private insurance; $\zeta=0.063$ for households under 65 with only public insurance; $\zeta=0.159$ for households over 65 with Medicare only; $\zeta=0.145$ for

\footnotetext{
${ }^{13}$ See, for example, Currie and Gruber (1997), Currie and Thomas (1995), Haas and Goldman (1994), Long, Marquis, and Rodgers (1997), and Tilford et al. (1999) who provide information on medical care use for the insured and uninsured.
} 
households over 65 with Medicare and some private insurance; and $\zeta=0.042$ for households over 65 with Medicare and supplemental public insurance.

Survival Probability: The survival function is given by the cumulative distribution function $\Psi(h)=1-\exp \left(-\psi h^{\sigma}\right)$.

Health Shocks: At each age, we assume that there are two possible values for the health shocks: $\varepsilon_{h}$ and $\varepsilon_{l}$. The first shock $\varepsilon_{h}$ corresponds to being healthy and is set to zero. The magnitude of the health shock $\varepsilon_{l}$ can vary by age and gender and is determined by the calibration procedure: $p_{55}, p_{65}, p_{75}, p_{85}$ and $p_{100}$ refer to 5-year probabilities of an adverse health shock between the ages of 0-55, 55-65, 65-75, 75-85 and 85+ respectively.

Sick Time: We assume that the amount of sick time is given by $s(h)=h^{-\alpha}$.

\subsection{Calibration}

While several parameters are set based on estimates from the literature or by estimating reduced form empirical models from the HRS, additional critical parameters still need to be specified. We use information on asset holdings, retirement age, life tables and medical expenses for the average household in the HRS to pin down these parameters.

The parameters we calibrate are $\lambda$, the utility weight on consumption relative to health; $\rho$, which determines the elasticity of substitution between consumption and health; $\vartheta$ and $v$, the parameters governing the aggregation of the husband and the wife's stock of health to determine the household's health stock; $\gamma$, the inverse of the intertemporal elasticity of substitution; $\psi$, the coefficient on health in the survival function; $\sigma$, the curvature of the survival function with respect to health; $\xi$, the curvature of the health production function; $\varepsilon_{l}$, the magnitude of the adverse health shock; $\chi$, the share parameter in health production between monetary and time inputs; $\delta_{h}$, the annual depreciation rate of health; $\alpha$, the elasticity of sick time with respect to health status; and $p_{55}, p_{65}, p_{75}, p_{85}$ and $p_{100}$, the probabilities of bad health shocks occurring at different age intervals separately for males and females. 
To calculate these remaining parameters, we solve the dynamic programming problem for married, single male, and single female "average" households, where average is defined as the household with average earnings and medical expenses over their lifetimes. We then use the decision rules in conjunction with observed histories of earnings and medical expenses to obtain model predictions. Notice that while we have earnings observations on an annual basis, we only have medical expenses starting in 1992. Hence, we integrate out the lifetime sequence of health shocks before arriving at the model predictions for a given age. We then seek to obtain the best fit between model and data relative to the moments we seek to match for these three types of households in 1998. We emphasize that the implicit assumption employed in our strategy is that households are identical in terms of preferences and technology but face different constraints due to the evolution of shocks in the face of incomplete markets. Males differ from females in terms of the probabilities of the adverse health shock as they age to account for the greater longevity of women relative to men.

The moments we use to identify and pin down the parameters are: ${ }^{14}$

1. Mean net worth in 1998 for married couples (husband age 63.2, wife age 60.9) is $\$ 508,904$

2. Mean net worth in 2008 for married couples is $\$ 628,599$

3. Mean net worth in 1998 for single males (age 64.1) is $\$ 295,486$

4. Mean net worth in 1998 for single females (age 66.7) is $\$ 193,064$

\footnotetext{
${ }^{14}$ Moments for net worth data and the retirement age come directly from HRS data. Moments for total medical expenses come from the National Health Expenditure Accounts (using the personal health spending totals by age for 2004), drawn from http://www.cms.gov/Research-Statistics-Data-and-Systems/StatisticsTrends-and-Reports/NationalHealthExpendData/Age-and-Gender-Items/CMS1242122.html. We disaggregate the National Health Expenditure Account total for married men, married women, single men, and single women using data from the Medical Expenditure Panel Study. The mortality probabilities come from the World Health Organization, http://www.who.int/healthinfo/statistics/mortality_life_tables/en/. The data on sick hours come from the PSID.
} 
5. The probability of dying between ages 50-54 for males: $3.08 \%$

6. The probability of dying between ages $70-74$ for males: $13.76 \%$

7. The probability of dying between ages $80-84$ for males: $31.69 \%$

8. The probability of dying between ages $90-94$ for males: $60.70 \%$

9. The probability of dying between ages 50-54 for females: $1.834 \%$

10. The probability of dying between ages $70-74$ for females: $9.57 \%$

11. The probability of dying between ages $80-84$ for females: $23.94 \%$

12. The probability of dying between ages $90-94$ for females: $52.05 \%$

13. Average annual total medical expenses for married women age 19-44: $\$ 4,454$

14. Average annual total medical expenses for married women age 50-54: $\$ 5,743$

15. Average annual total medical expenses for married women age 60-64: $\$ 7,747$

16. Average annual total medical expenses for married women age $70-74$ : $\$ 12,417$

17. Average annual total medical expenses for married women age $80+$ : $\$ 17,896$

18. Average annual total medical expenses for single women age 70-74: $\$ 12,479$

19. Average annual total medical expenses for married men age 70-74: $\$ 13,225$

20. Average annual total medical expenses for single men age $70-74$ : $\$ 13,474$

21. Sick hours relative to total work hours at age 40: 0.015

22. Retirement Age: 62 
The model with each calibrated parameter generates 22 non-linear equations with 22 unknowns. We obtained an exact match between the model predictions and the moments listed above. The resulting parameter values are given below.

\begin{tabular}{|l|l|l|l|l|l|}
\hline Parameter & $\lambda$ & $\rho$ & $\vartheta$ & $v$ & $\gamma$ \\
\hline Value & 0.71 & -4.1 & 0.49 & 0.73 & 0.78 \\
\hline Parameter & $\psi$ & $\sigma$ & $\xi$ & $\varepsilon_{l}$ & $\chi$ \\
\hline Value & .0012 & 1.53 & 0.69 & -14.4 & 0.49 \\
\hline
\end{tabular}

\begin{tabular}{|l|l|l|l|l|l|l|}
\hline Parameter & $p_{55}$ & $p_{65}$ & $p_{75}$ & $p_{85}$ & $p_{100}$ & $\delta_{h}$ \\
\hline Value & 0.06 & 0.11 & 0.139 & 0.197 & 0.245 & 0.042 \\
\hline Parameter & $p_{55, f}$ & $p_{65, f}$ & $p_{75, f}$ & $p_{85, f}$ & $p_{100, f}$ & $\alpha$ \\
\hline Value & 0.04 & 0.09 & 0.119 & 0.168 & 0.229 & 0.17 \\
\hline
\end{tabular}

The value of $\gamma$ is equal to 0.78 , which implies an intertemporal elasticity of substitution $(1 / \gamma)$ of 1.28. This number is not comparable with the Euler equation based estimates of the IES since most studies estimating the IES use standard time additively separable preferences. The elasticity of substitution between consumption/leisure composite and health is $\frac{1}{1-\rho}=0.2$. Consumption and health are complements and our calibrated value is very close to the estimates in Finkelstein, Luttmer, and Notowidigdo (forthcoming). In a married household, the male and the female's health are very good substitutes as reflected by $v=0.73$. The rate of depreciation of health is 4.2 percent per year. The share of goods in the production of health $\chi$ is 0.49 , suggesting that time and goods are both important in the production of health. The bad health shock, $\varepsilon_{l}$, takes on the value -14.4 (recall that the good health shock $\varepsilon_{h}$ is set to 0 ). Finally, note that the 5 -year realization probability of the bad health shock increases from 6 percent for men ( 4 percent for women) below 55 years of age to 11 percent ( 9 percent for women) for men between 55 and 65, to 13.9 percent (11.9 percent for women) for men between 65 and 75 , to 19.7 percent (16.8 percent for women) for households between 75 and 85 , and to 24.5 percent (22.9 percent for women) for men above the age of 85 . 
As mentioned above, we match 22 data moments with the model to identify these 22 parameters. Clearly, altering one of the target data moments changes more than one parameter. Nevertheless, it is instructive to think about which data moments play a critical role for at least some of the more important parameters.

A lower value of $\rho$ will lead to a higher level of assets in 1998. In addition, a lower value of $\rho$ will have implications for asset accumulation/decumulation late in life. Predictable declines in health ought to be associated with predictable declines in consumption. Hence having asset levels in 1998 as well as 2008 helps pin down $\rho$.

The parameters governing the production technology for health (for males) as well as the hazard function are pinned down by the mortality probabilities as well as medical expenses. Recall that health affects both utility as well as mortality. The importance of health in utility $(\lambda)$ as well as the significance of health in improving longevity are both simultaneously pinned down by these moments. The probabilities of dying as people age interact with the technology for producing health to determine medical expenses. For instance, if diminishing returns set in quickly, substantial medical expenses need to be expended simply to maintain the stock of health. In contrast, if the medical technology were close to linear, then additional medical expenses will have a large effect on the stock of health. Hence, all these objects (medical technology parameters, importance of health relative to consumption in utility), as well as the parameters of the hazard function, are simultaneously pinned down by the probabilities of the bad shock and medical expenses as men age.

Medical expenses for single women and probabilities of dying for men relative to women help pin down the probabilities of bad health shocks for women. In addition, mean net worth for singles relative to married couples shed light on the health aggregator in preferences. A change in the parameters governing the health aggregator for married households $(\vartheta, v)$ will affect both the wealth of the married household as well as medical expenses for married women relative to single women. 


\subsection{Model Solution}

With the calibrated parameters, we solve the dynamic programming problem by linear interpolation on the value function. For each household in our sample, we compute optimal decision rules for assets and the stock of health from the oldest possible age (assumed to be 120 ) to the beginning of working life $(S)$ for any feasible realizations of the random variables: earnings and health shocks. These decision rules differ for each household, since each faces stochastic draws from different earnings distributions (recall they are household specific). Household-specific earnings expectations also directly influence expectations about social security and pension benefits. Other characteristics also differ across households. We then use the decision rules and the observed earnings and medical expenses to obtain the model's predictions for wealth, health, medical expenses and mortality at a given age. Where we do not have annual data on medical expenses or earnings, we use the distributions of earnings shocks or health shocks to integrate out expected medical expenses and earnings.

\section{Results}

As emphasized in the previous discussion, we calibrate key model parameters to the average (married, single male and single female-headed) HRS household in 1998. The first question we address, therefore, is how the model matches household wealth, out-of-pocket medical expenses, and the stock of health. We summarize results for household wealth and outof-pocket medical expenses by showing median values, breaking households into lifetime income quintiles. ${ }^{15}$

\footnotetext{
${ }^{15}$ Lifetime income is defined within four roughly equal-sized age groups: under 60,60 to 65,66 to 75 , and over 75 .
} 


\begin{tabular}{|l|c|c|c|c|}
\hline \multicolumn{1}{|c|}{ Table 1: Median Net Worth and Out-of-Pocket Medical Expenditures, Model and Data, 1998 and 2008} \\
\hline Lifetime Income & \multicolumn{2}{|c|}{ Median Net Worth } & Median OOP Medical Expenses \\
\hline \hline Lowest Quintile & $\$ 33,588$ & $\$ 23,596$ & Data & Model \\
\hline Second Quintile & 60,717 & 47,506 & 904 & $\$ 735$ \\
\hline Middle Quintile & 97,212 & 94,503 & 995 & 945 \\
\hline Fourth Quintile & 180,859 & 151,203 & 930 & 982 \\
\hline Highest Quintile & 340,144 & 322,309 & 1,023 & 1,012 \\
\hline \multicolumn{1}{|c|}{2008} & & & & $\$ 632$ \\
\hline Lowest Quintile & $\$ 15,495$ & $\$ 15,283$ & $\$ 640$ & 921 \\
\hline Second Quintile & 63,900 & 57,495 & 1,080 & 1,146 \\
\hline Middle Quintile & 136,000 & 127,503 & 1,200 & 1,323 \\
\hline Fourth Quintile & 238,000 & 253,991 & 1,384 & 1,589 \\
\hline Highest Quintile & 443,000 & 422,405 & 1,680 & 964 \\
\hline
\end{tabular}

There are two striking features of Table 1. First, while we calibrate the model to

the average household in 1998, the model does a good job matching the wide variation in wealth across low and high lifetime income households in 1998. The correlation of actual and optimal net worth in 1998 is 0.69. Scholz, Seshadri, and Khitatrakun (2006) report a correlation between model predications and net worth in the HRS of 0.86 in 1992. There are a number of differences between our earlier work and this paper. The most important is that health affects utility and longevity, households make endogenous health investments, we model the health decisions of spouses, retirement is endogenous, preferences are not time-additively separable, new cohorts have been added to the data and we now look at a much more recent period, and we have new estimates of the earning process, which show somewhat more volatility in earnings than our previous estimates, among other changes. Despite these differences, our earlier qualitative conclusion still holds: Most Americans seem to be preparing well for financially secure retirements. 
Predicted out-of-pocket median medical expenses also match actual expenses fairly closely. For instance, in 1998, the out-of-pocket medical expenses rise from $\$ 735$ for the lowest lifetime income quintile to $\$ 1,012$ for the highest income quintile. This tracks the data pretty closely. Richer households spend more out-of-pocket (despite possessing better health on average at the same age) and these investments affect both flow utility as well as longevity. The household-by-household correlation between actual out-of-pocket medical expenditures and optimal out-of-pocket medical expenditures in the model is 0.50 .

The second striking feature of Table 1 is the degree to which we match the dispersion of median net worth and out-of-pocket medical expenditures by lifetime income quintile in 2008. We use only one net worth moment for 2008 (the net worth of married couples): health expenses are for 2004 (due to the timing of the National Health Expenditure Accounts). Yet the behavioral model augmented with preference parameters calibrated to the average household in 1998, data on changes in household composition, and earnings realizations (for those still in the labor market) is able to closely match the 2008 distribution of median net worth and out-of-pocket health spending.

Another feature of the HRS are questions on self reported health status, which we used in Figures 1 and 3. Households report this on a 5-point scale ranging from poor to excellent. In the model, the stock of health is a continuous variable and hence to compare with the data, we turn the continuous health variable into a discrete one. In the HRS data, 13 percent of the sample report excellent health, 28 percent report very good, 30 percent report good, 19 percent report fair and 9 percent report poor. We choose the cut-off points in the continuous distribution so that these percentages are what we observe in the HRS. Table 2 depicts the connection between the model and data for 1998 and 2008 in more detail. 


\begin{tabular}{|c|c|c|c|c|c|c|c|c|c|c|}
\hline & \multicolumn{10}{|c|}{ Fraction of Households by Self-Reported Health Status } \\
\hline Lifetime Income & \multicolumn{2}{|c|}{ Excellent } & \multicolumn{2}{|c|}{ V. Good } & \multicolumn{2}{|c|}{ Good } & \multicolumn{2}{|c|}{ Fair } & \multicolumn{2}{|c|}{ Poor } \\
\hline 1998 & Data & Model & Data & Model & Data & Model & Data & Model & Data & Model \\
\hline Bottom Quintile & 7 & 7 & 17 & 15 & 28 & 29 & 28 & 29 & 19 & 18 \\
\hline Second Quintile & 10 & 9 & 20 & 21 & 28 & 26 & 26 & 27 & 16 & 17 \\
\hline Middle Quintile & 12 & 12 & 23 & 22 & 33 & 34 & 21 & 20 & 11 & 12 \\
\hline Fourth Quintile & 13 & 14 & 29 & 28 & 34 & 33 & 18 & 19 & 7 & 6 \\
\hline Highest Quintile & 18 & 19 & 36 & 35 & 30 & 29 & 12 & 12 & 4 & 5 \\
\hline 2008 & & & & & & & & & & \\
\hline Bottom Quintile & 5 & 6 & 18 & 19 & 28 & 27 & 31 & 30 & 18 & 18 \\
\hline Second Quintile & 7 & 7 & 22 & 21 & 31 & 30 & 26 & 27 & 13 & 15 \\
\hline Middle Quintile & 9 & 10 & 26 & 24 & 33 & 32 & 23 & 24 & 9 & 10 \\
\hline Fourth Quintile & 10 & 10 & 32 & 31 & 33 & 32 & 19 & 19 & 7 & 8 \\
\hline Highest Quintile & 12 & 12 & 37 & 34 & 33 & 33 & 13 & 14 & 5 & 7 \\
\hline
\end{tabular}

There is a very tight link between lifetime income and the self-reported health status and the model does an excellent job at tracking the variation in the data. Various model features come into play here - as households age, they receive adverse shocks with greater intensity. Their ability to buffer these shocks depends largely on health investments they had made in the past (which determines their current health status), as well as their income. The pace at which health deteriorates in older ages also affects consumption (recall that consumption and health are complements), which in turn affects wealth accumulation. The fact that the model is able to match the extent to which health worsens between 1998 and 2008 adds to our confidence that the model provides a reasonable description of the evolution of health by lifetime income.

The central object of attention in this paper is retirement, which is endogenous. Table 
3 gives the fit between model and data on retirement age.

\begin{tabular}{|l|c|c|c|c|c|c|c|c|c|c|}
\hline Table 3: Retirement Age, Model Prediction and HRS Data \\
\hline & \multicolumn{9}{|c|}{ Median Retirement Age by Self Reported Health Status } \\
\hline Lifetime Income & \multicolumn{2}{|c|}{ Excellent } & \multicolumn{2}{|c|}{ V. Good } & \multicolumn{2}{|c|}{ Good } & \multicolumn{3}{|c|}{ Fair } & \multicolumn{3}{c|}{ Poor } \\
\hline \hline & Data & Model & Data & Model & Data & Model & Data & Model & Data & Model \\
\hline Bottom Quintile & 61 & 60 & 61 & 61 & 60 & 59 & 57 & 58 & 54 & 55 \\
\hline Second Quintile & 60 & 61 & 63 & 62 & 62 & 61 & 61 & 61 & 57 & 57 \\
\hline Middle Quintile & 62 & 62 & 62 & 62 & 62 & 62 & 60 & 61 & 60 & 59 \\
\hline Fourth Quintile & 62 & 62 & 62 & 63 & 62 & 63 & 62 & 62 & 61 & 60 \\
\hline Highest Quintile & 63 & 63 & 63 & 63 & 63 & 63 & 63 & 63 & 63 & 63 \\
\hline
\end{tabular}

In the data, low lifetime income households with poor health status retire very early (age

54 ) while the majority of households retire at 62 . The early retirement of poor households is triggered by the early onset of bad health shocks. These households typically have low earnings options and hence choose (or are forced) to retire early. Richer households who have better health expect to live longer and hence choose to retire later, partly to finance a longer retirement period.

The model does a very good job matching the distribution of health, wealth and retirement ages. As is fairly clear from the above discussion, the interplay between health and wealth is critical in explaining retirement decisions as well. The model presents an ideal laboratory in which to analyze the implications of wealth shocks and changes in social security policy on retirement decisions. In what follows, we present two experiments to isolate the impact of exogenous changes on retirement decisions.

Economic Shocks: Our first thought experiment addresses the role played by wealth shocks on retirement decisions. Consider first a sudden and unexpected shock that results in a $20 \%$ decline in wealth. The stock market declines in the recent years may be thought of as a very large shock affecting households near retirement. What is the impact of this on economic decisions? Since poorer households are less reliant on private savings to finance 
retirement, an adverse wealth shock has a much smaller impact on their decisions than it will for richer households (we are implicitly assuming the macroeconomic shock does not affect the generosity of Social Security and Medicare). Consequently, richer households experience a greater decline in consumption than poorer households.

In this experiment, we assume that households receive this unanticipated shock at age 55. We then proceed to simulate the model under the new starting values for initial assets at age 55. We recompute all economic decisions including the decision to retire and allow households to come back from retirement if they find it optimal to do so.

As expected, the decline in wealth results in an increase in the median retirement age. The $20 \%$ shock to wealth induces households to postpone retirement by one year with households at the low end of the distribution remaining relatively unaffected. The magnitude of this increase is smaller than it would be if health were treated exogenously. In response to the decline in wealth, households react by cutting health expenditures as well - this increases mortality. The reduction in expected lifetimes leads households to save less than they would otherwise since their horizon is shorter than they had previously anticipated.

Changes in Early Eligibility Age (EEA): An important issue concerning social security policy is the effects of changes in the EEA. The EEA is the youngest age that a worker can obtain social security benefits and is currently 62. Many workers begin to draw their Social Security retirement benefits at age 62 or shortly thereafter. Retired-worker benefits beginning exactly at age 62 are 70 to 80 percent of the full retirement benefit, depending on the specific year the worker retired. Raising the EEA would result in many workers receiving larger monthly benefits at older ages, when workers may be less able to supplement their benefits with earnings from work. However, raising the EEA could adversely affect individuals with low incomes, who tend to have poorer health and rely more than others on Social Security benefits. It is interesting to note that various discussions of increasing the EEA deal primarily with the concern that changes in EEA could adversely affect households 
with poor health status. Our framework with endogenous health is well suited for dealing with this issue.

Consider an unanticipated increase in the EEA from 62 to 65 when households are 55 years old. To be clear, this household was making decisions under the assumption that reduced benefits were available starting age 62 and had been making economic decisions about consumption, saving, health investments, and future retirement accordingly. When the household is 55 years of age, the EEA is unexpectedly increased to 65 . The household has some time to react by reducing consumption and increasing savings to plan for the lack of social security benefits, if they indeed had planned on claiming social security benefits prior to the new EEA of 65. Clearly, this policy affects poorer households more than richer households, who generally rely less than do the poor on social security benefits.

In response to the increase in EEA, households decrease their consumption from age 55 (the age at which they receive news on the change in policy) onwards and increase their savings. As anticipated, the effect is more pronounced for poor households. Another consequence of this change is an increase in the median retirement age, which rises from 62 to 64 . Finally, while households spend a little less on medical expenses, the longer working horizon that households choose goes a long way towards mitigating the adverse consequences for health. Hence, the stock of health at age 62 is not very much affected and mortality remains similar to the baseline model. We conclude that changes in the EEA result in large changes in the age of retirement, but has rather small effects on the health status of most households.

\section{Conclusion}

In this paper, we describe a lifecycle model of consumption with endogenous investments in health. Health affects longevity as well as utility and retirement decisions. We solve the model household-by-household using data from the HRS. We force the model to match mo- 
ments on wealth, retirement, mortality, and medical expenses for the average HRS married and single households, calibrating 22 parameters. We take these parameters as primitives for all households and vary the circumstances of the households based on observables in the HRS data such as earnings and medical expense realizations, insurance status, marital status, and demographic variables. We then ask whether this framework with the 22 parameters identified by the typical household can account for the microeconomic variation in health, wealth, mortality and retirement across the 11,172 households we analyze. We find that it can. Our study suggests that the interplay between retirement decisions, health and wealth is rather complex, but that these decisions are intertwined. Studying them jointly has not been done so far.

We use our framework to conduct two thought experiments. First, we analyze the impact of a shock to wealth near retirement. A $20 \%$ reduction in wealth (due to a macroeconomic shock) results in the median household delaying retirement by a year. This effect is smaller than it would have been if health were assumed to be unaffected by such a large shock - our model predicts that a large reduction in wealth near retirement has non-trivial consequences for health as well as mortality. The increase in mortality implies a smaller response to retirement since households plan on a shorter expected lifetime. Second, we look at the impact of increasing the EEA for claiming social security benefits from 62 to 65. This shock affects poor households disproportionately since they are more reliant than others on Social Security. The increase in EEA from 62 to 65 results in a very large increase in the retirement age - from 62 to 64 for the average household. This change does not affect health all that much and mortality remains largely unaffected - households counter the reduced resources from ages 62 to 64 by working more and hence maintaining their investments in health at roughly their pre-existing levels. 


\section{References}

[1] Becker, G. S., 1964, Human Capital : A Theoretical and Empirical Analysis, with Special Reference to Education. New York: National Bureau of Economic Research.

[2] Card, David, Carlos Dobkin, Nicole Maestas, "Does Medicare Save Lives?" Quarterly Journal of Economics, May 2009, Vol. 124, No. 2: 597-636.

[3] Case, Ann and Angus Deaton, "Broken Down by Work and Sex: How Our Health Declines," in D. Wise (ed.) Advances in the Economics of Aging. University of Chicago Press, 2005.

[4] Citro, Constance F. and Robert T. Michael. 1995. Measuring Poverty: A New Approach. Washington, D.C.: National Academy Press.

[5] Chay, Kenneth Y., Daeho Kim, and Shailender Swaminathan, 2010, "Medicare, Hospital Utilization and Mortality: Evidence from the Program's Origins," working paper.

[6] Cooley, Thomas F. and Ed Prescott, 1995, "Economic Growth and Business Cycles," Chapter 1 in T. F. Cooley, ed., Frontiers of Business Cycle Research, (Princeton University Press), 1-38.

[7] Currie, Janet and Jonathan Gruber. "The Technology of Birth: Health Insurance, Medical Interventions, and Infant Health.” NBER Working Paper. No. 5985. 1997.

[8] Currie, Janet and Duncan Thomas. "Medical Care for Children: Public Insurance, Private Insurance, and Racial Differences in Utilization." Journal of Human Resources. 30(1). 1995: 135-62.

[9] Danziger, S., R. Haveman and R. Plotnick. 1981. "How Income Transfer Programs Affect Work, Savings, and the Income Distribution: A Critical Review." Journal of Economic Literature 19 (September): 975-1028. 
[10] De Nardi, Mariacristina, Eric French, and John Bailey Jones, 2010, "Why Do the Elderly Save? The Role of Medical Expenses," Journal of Political Economy, University of Chicago Press, vol. 118(1), pages 39-75, 02.

[11] Doyle, Joseph J, Jr, "Health Insurance, Treatment and Outcomes: Using Auto Accidents as Health Shocks," NBER Working Paper 11099, February 2005

[12] Doyle, Joseph J, Jr, "Returns to Local-Area Health Care Spending: Using Health Shocks to Patients Far from Home," May 2009. http://www.mit.edu/ jjdoyle/doyle_vacation_aer_may2009.pdf

[13] Engen, Eric M., William G. Gale and Cori R. Uccello. 1999. "The Adequacy of Retirement Saving." Brookings Papers on Economic Activity 2: 65-165.

[14] Finkelstein, Amy, Erzo Luttmer, and Matthew Notowidigdo, forthcoming, "What Good is Wealth without Health? The Effect of Health on the Marginal Utility of Consumption," Journal of the European Economic Association

[15] Finkelstein, Amy and Robin McKnight, 2008, "What Did Medicare Do? The Initial Impact of Medicare on Mortality and Out of Pocket Medical Spending," Journal of Public Economics, 92, 1644-1669.

[16] French, Eric, 2005. "The Effects of Health, Wealth, and Wages on Labour Supply and Retirement Behaviour," Review of Economic Studies, Wiley Blackwell, vol. 72(2), pages 395-427.

[17] Fonseca, Raquel, Pierre-Carl Michaud, Titus Gamama, and Arie Kapteyn, 2009, "On the Rise of Health Spending and Longevity," IZA Discussion paper \#4622

[18] Gouveia, Miguel and Robert R. Strauss. 1994. "Effective Federal Individual Income Tax Functions: An Exploratory Empirical Analysis." National Tax Journal 47(2) (June): 317-39. 
[19] Gouveia, Miguel and Robert R. Strauss. 1999. "Effective Tax Functions for the U.S. Individual Income Tax: 1966-89." Proceedings of the 92nd Annual Conference on Taxation, National Tax Association: 155-65.

[20] Grossman, Michael, 1972, "One the Concept of Health Capital and the Demand for Health," Journal of Political Economy, 80, 223-255

[21] Gustman, A. L. and T. L. Steinmeier. 1986. "A Structural Retirement Model." Econometrica 54 (May): 555-584.

[22] Haas, J. S. and L. Goldman. "Acutely Injured Patients with Trauma in Massachusetts: Differences in Care and Mortality, by Insurance Status." American Journal of Public Health. 84(10). October 1994: 1605-1608.

[23] Hall, Robert and Charles Jones. 2007. "The Value of Life and the Rise in Health Spending," Quarterly Journal of Economics, February.

[24] Hubbard, Glen R., Jonathan Skinner, and Stephen P. Zeldes. 1995. "Precautionary Saving and Social Insurance." Journal of Political Economy, 103(2) (April): 360-99.

[25] Krueger, A. and B. Meyer. 2002. "Labor Supply Effects of Social Insurance." In Handbook of Public Economics, Vol. 4, ed. A. Auerbach and M. Feldstein. Chicago: University of Chicago Press.

[26] Laitner, John and Dan Silverman (2005). "Estimating Life-Cycle Parameters from Consumption Behavior at Retirement", NBER Working Paper 11163.

[27] Long, S.H., M.S. Marquis, and J. Rodgers. "Do people Shift Their Use of Health Services over Time to Take Advantage of Insurance?" Journal of Health Economics. 17. 1997: 105- 115 
[28] Lumsdaine, R. and O. Mitchell. 1999. "New Developments in the Economic Analysis of Retirement." In Handbook of Labor Economics, Vol. 3C, ed. Ashenfelter, O. and D. Card. Amsterdam: North-Holland.

[29] McGarry, Kathleen, 2004. "Health and Retirement: Do Changes in Health Affect Retirement Expectations?" Journal of Human Resources 39(3): 624-648

[30] McGrattan, Ellen R. and Edward C. Prescott. 2003. "Average Debt and Equity Returns: Puzzling?" American Economic Review Papers and Proceedings. 93(2) (May): 392-397.

[31] Mermin, Gordon B.T., Richard W. Johnson, and Dan Murphy, 2006, "Why Do Boomers Plan to Work So Long?" Urban Institute, Retirement Project Working Paper 06-04, December.

[32] Mincer, J., 1974, Schooling, Experience and Earnings, Columbia University Press, New York, 1974.

[33] Moffitt, Robert. 2002. "Documentation for Moffitt Welfare Benefits File." Manuscript, February 22, http://www.econ.jhu.edu/People/Moffitt/DataSets.html.

[34] Murphy, Kevin M. and Topel, Robert H. (2006). "The Value of Health and Longevity," Journal of Political Economy 114 (5):871-904.

[35] Palumbo, Michael G. 1999. "Uncertain Medical Expenses and Precautionary Saving Near the End of the Life Cycle." Review of Economic Studies 66(2): 395-421.

[36] Rosen, Sherwin. 1988. "The Value of Changes in Life Expectancy," Journal of Risk and Uncertainty 1 (September): 285-304.

[37] Scholz, John Karl and Ananth Seshadri. 2012. "Health and Wealth in a Lifecycle Model," mimeo, University of Wisconsin-Madison. 
[38] Scholz, John Karl, Ananth Seshadri, and Surachai Khitatrakun. 2006. "Are Americans Saving 'Optimally' for Retirement?' Journal of Political Economy. August, 607-643.

[39] Smith, James P., "Consequences and Predictors of New Health Events," in D. Wise (ed.) Advances in the Economics of Aging. University of Chicago Press, 2005.

[40] Tilford, J.M., Robbins, J.M., Shema, S.J., and F.L. Farmer. "Response to Health Insurance by Previously Uninsured Rural Children." Health Services Research 34(3). 1999: 761-775.

[41] Yogo, Motohiro, 2009, "Portfolio Choice in Retirement: Health Risk and the Demand for Annuities, Housing, and Risky Assets," mimeo 